\title{
ISOLATED POLYOSTOTIC FIBROUS DYSPLASIA: A DIFFERENTIAL DIAGNOSIS IN A TEENAGE PATIENT
}

Gilberto Scanagatta ${ }^{1, *}$, Tatiana Freitas Tourinho ${ }^{1}$, Maria Lucia Lemos Lopes ${ }^{1}$, Maria Odete Esteves Hilario', Eduardo Rosa de Oliveira ${ }^{1}$, Thiago Willers ${ }^{1}$, Rafael Coradin ${ }^{1}$, Raissa Velasques de Figueiredo ${ }^{1}$, Bruno Trevisan ${ }^{1}$, Gabriela Sasso Padilha ${ }^{1}$, Luana Ribeiro Carlos ${ }^{1}$

1. Universidade Federal de Ciências da Saúde de Porto Alegre, Porto Alegre (RS), Brazil.

*Corresponding author: gilberto_scanagatta@hotmail.com

\section{BACKGROUND}

Fibrous dysplasia is a type of benign neoplasm where the bone is replaced by fibrous connective tissue and malformed trabecular bone tissue. It corresponds to 5 to $7 \%$ of benign bone tumors in children and adolescents. This pathology can affect one or multiple bones, classified as monostotic and polyostotic, respectively. Generally, the polyostotic form is accompanied by other genetic disorders (café-au-lait macules, endocrine abnormalities and soft tissue myxomas) that are part of McCune-Albright syndrome and/or Mazabraud syndrome. In this report, we present a case of a patient with an isolated form of polyostotic fibrous dysplasia.

\section{CASE REPORT}

The patient in question is a 34-year-old woman, married and mother of 2 children. At 14 years old, she fractured both forearms after falling off her bicycle. In the first radiographic evaluation, the presence of osteolytic lesions in proximal thirds of both radios was evidenced. Surgical fixation of the fractures was performed and material for anatomopathology was collected. No other compatible clinical finding of McCune-Albright syndrome was found during pediatric evaluation. At the age of 18 , she underwent a new evaluation and was followed up by a rheumatologist. During the course of the disease, the patient presented 7 new fractures of the left forearm. She has a stable disease, without deformities and receiving treatment with alendronate $70 \mathrm{mg} / \mathrm{week}$, vitamin D $14,000 \mathrm{UI} /$ week and physical therapy.

\section{CONCLUSION}

Polyostotic fibrous dysplasia is a disorder that makes up the McCune-Albright/Mazabraud syndrome phenotype; however, in rare cases, it can appear in isolation. Patients with this type of pathology require specialized and multidisciplinary monitoring, due to the risk of recurrence of fractures, the appearance of deformities and the possibility of malignant transformation of the lesions. The case addressed shows the good clinical evolution of a patient who received early diagnosis, treatment and maintained a good link with the medical team in their longitudinal evaluation. 